\title{
Some Challenges in Gravity Related Research
}

\author{
Jack J. W. A. van Loon ${ }^{1,2 *}$ \\ ${ }^{1}$ Department of Oral and Maxillofacial Surgery/Oral Pathology, Amsterdam UMC Location VUmc, Academic Center for \\ Dentistry Amsterdam (ACTA), Vrije Universiteit Amsterdam, Amsterdam, Netherlands, ${ }^{2}$ ESTEC, TEC-MMG-Lab, European \\ Space Agency (ESA), Noordwijk, Netherlands
}

Keywords: mechanosensing, hypergravity, clinostats, RPM, fluid physics, convection, solidification

\section{OPEN ACCESS}

\section{Edited and reviewed by:}

Guglielmo S. Aglietti,

The University of Auckland,

New Zealand

*Correspondence:

Jack J. W. A. van Loon j.vanloon@amsterdamumc.nl

Specialty section:

This article was submitted to Microgravity,

a section of the journa Frontiers in Space Technologies

Received: 12 May 2020

Accepted: 25 May 2020

Published: 16 June 2020

Citation: van Loon JJWA (2020) Some Challenges in Gravity Related Research. Front. Space Technol. 1:3. doi: $10.3389 /$ frspt.2020.00003
"Microgravity" is not a science, as some presume, but a particular environment where science can be performed. The main reason behind performing basic sciences under such microgravity, free fall, or conditions of near weightlessness is indeed that the weight is removed from the mass. This results in less mechanical stress within a system, less or nearly no convection, reduced pressure differences within a system, etc.

In such an environment, one can also observe phenomena that are otherwise obscured or blurred when studied in a gravitational field, such as thermo-capillary Bénard-Marangoni convection or surface-tension-dominated Gibbs-Marangoni convections, capillary flows, critical point phenomena, and many more related issues in physical sciences and engineering. Items of study include colloids, emulsions, foams, liquid crystals, dusty plasmas, flames/combustion or granular material, and also fundamental particle physics, e.g., Bose-Einstein condensates, or more bulk processes, such as alloy solidification (see also Monti, 2002).

Current and past platforms for long-duration microgravity are the Russian Photon and Bion satellites (Nikolaev and Ilyin, 1981; Ilyin, 2000), the Space Shuttle (Crippen and Young, 2011) and Soyuz missions (Van Loon et al., 2007), and the Salyut, Skylab (NASA, 1973; Michel et al., 1976), Mir, and ISS (Evans et al., 2009; Ruttley et al., 2017) space stations or the Chinese Shenzhou spacecraft (e.g., Preu and Braun, 2014; Hu and Kang, 2019), the future Chinese Space Station (e.g., Wang et al., 2019), or its predecessor facilities, such as the TongGong Spacelab (Gu et al., 2016; Li et al., 2018; Wang et al., 2018).

A large part of the science does not, however, require a long duration of near weightlessness and can make use of platforms such as parabolic aircrafts (Pletser and Kumei, 2015), drop towers (Von Kampen et al., 2006), or sounding rockets (European Space Acency, 2014), and this includes the more recent commercial suborbital platforms such as the Blue Origin New Shepard (Blue Origin, 2017), the Virgin Galactic White Knight (Virgin Galactic, 2016), the Dream Chaser from Sierra Nevada Company (Taylor et al., 2014), or the upcoming Space Rider from the European Space Agency (Fedele et al., 2018). Finally, the SpaceX Dragon module and the DragonLab are and will be used extensively for gravity and space-related sciences (Dreyer, 2009; Seedhouse, 2016). There is therefore going to be a wealth of flight platforms that can be of use for microgravity science and technology experiments.

Besides basics sciences where we make use of the microgravity environment, we also have the operational sciences where we have to cope with the microgravity environment. In operational sciences, which is often also referred to as applied sciences, one needs to develop and use systems for both physical and life sciences fields that facilitate existence within such an environment. For example, all fluidic and two-phase systems need to remain functional without the sedimenting force of gravity in all kinds of fluid-filled systems in space stations but also in fuel tanks for other satellites.

Additionally, humans need to be able to work also, in the future, within a free-falling system. However, the latter does pose serious problems with respect to human health. Numerous 
so-called "countermeasures" (or should one say "therapies") have been developed in order to prevent human physiology to go into a pathological state. In cosmonauts, astronauts, and taikonauts, we see disorders like osteo- and sarcopenia, cardiovascular deconditioning, impaired cognitive performance, Spaceflight Associated Neuro-ocular Syndrome (SANS), reduced immune sensitivity, renal stones, loss of quality and duration of sleep, lower back pain, post-flight balance and coordination issues, and orthostatic intolerance or spinal compression with intervertebral disk damage-just to name a few (Stepanek et al., 2019). Some might question if the current lack of proper microgravity therapies is compliant with ethical labor and legal standards (Van Loon et al., 2020). This new journal would also be available to receive manuscripts concerning the development and test of instruments concerning the mitigation or full "recovery" of chronic microgravity and gravity transitions. Besides, for example, high-impact training (Sibonga et al., 2019) or Lower Body Negative Pressure (LBNP) devices (Goswami et al., 2019) we might explore the application of centrifuges to actually generate in-flight artificial gravity. Short arm systems are the most obvious ones (Kanikowska et al., 2008; Frett et al., 2014; Rittweger et al., 2015), although such systems generate a steep body gradient of gravity, and not all organs may be exposed to a sufficient gravity level. One may also look into rotating the complete spacecraft (Young et al., 2009; Paloski and Charles, 2014). In such systems, there is a more evenly distributed gravity level, and the subjects are chronically exposed to the artificial gravity like on Earth. However, such systems require a better understanding on long duration rotation for both humans and engineering (Lackner and Dizio, 2000; Joosten, 2007; Hall, 2016). Ground-based facilities could be used to address such in-flightrelated questions at the same time as they address the use of systems for health care (e.g., aging and obesity) and athleticsrelated applications (Van Loon et al., 2012).

The impact of gravity on small, low-mass systems is still puzzling. More than half a century ago, Pollard published a paper indicating that, from a biophysics point of view, weightlessness is not expected to have a significant effect at the level of a single cell (Pollard, 1965). Possible "gravisensors" in a non-specialized cell might be the mitochondria or the nucleolus. Later, Todd (1989) and Albrecht-Buehler (1991) published interesting papers, which are still quite relevant, addressing a series of forces that are involved at a small scale cellular level and compared them to the force of gravity at that micro scale.

Therefore, although there have been numerous experiments in space and on the ground showing the effect of gravity, or the lack thereof, on cells, the actual sensing mechanism in non-specialized cells has yet to be described. In an in-vitro model monolayer single cell with a diameter of $10 \mu \mathrm{m}$, the gravitational energy of an apparent weight of $0.5 \mathrm{pN}$ at an average distance of the radius $(5 \mu \mathrm{m})$ above the lowest point of the cell is $\sim 500 \mathrm{kT}$, where $\mathrm{k}$ is Boltzmann's constant, and $\mathrm{T}$ is absolute temperature (Vorselen et al., 2014). These are small forces and energies compared to other intra- and extra-cellular forces.

Numerous studies have been performed to explore the effect of weight or near weightlessness on cells. These studies have been, partially pushed by contemporary techniques, focused on the genetic effects (Karouia et al., 2017), although this is moving more and more toward proteomics/metabolomics and the actual physiology, while it is possible that adapted phenotypes or sometimes pathological changes can be noted. All these findings are in the area of mechano-transduction and mechano-adaptation (see Figure 1), while the holy grail and grand challenge in this field would be to identify a gravisensor (if such a thing exists). Most-if not all-the effects reported from altered gravity research in cell biology should start, at some point, with a mechanical, conformational, or frequency change within the system. It is this gravi- or mechano-sensor that should be identified. More advanced in-flight research opportunities and technologies are required for this, which is similar to what is used in the field of biomechanics, especially in molecular (Bao et al., 2010), cellular (Van Loon, 2007a), and tissue biomechanics (Trepat et al., 2007; Mohagheghian et al., 2018), but also on an organ and organism level. Instruments like femtosecond lasers (Ardeshirpour et al., 2018), microscopes with advanced imaging modalities like FLIM or FRET (see also De Vos et al., 2014; Corydon et al., 2016), atomic force microscopes (Van Loon et al., 2009; Zhou et al., 2018), optical tweezers (Bianchi et al., 2020),or micro-aspiration techniques (Janmaleki et al., 2016; González-Bermúdez et al., 2019) could have a prominent role in the quest for a gravity mechanosensory, especially in non-specialized cells (see Figure $\mathbf{1}$ left side). Systems like the FLUMIAS (Corydon et al., 2016; Thiel et al., 2019), the Light Microscopy Module (LMM), or the JAXA microscope (Ishioka et al., 2004) adapted plate readers or equivalents, which could also be quite illustrative concerning molecular conformational changes or interactions, e.g., with plate readers (as achieved by Kohn, 2013) or the NanoRacks plate reader, micro-NMR systems (Lee et al., 2015), or specific in vivo probes that reflect biophysical properties in molecules depending on their extra-molecular environment (e.g., Nakanishi et al., 2001; Woodcock et al., 2019). Manuscripts covering the technological developments of in-flight micro-or partial gravity platforms as well as on-ground versions to be used in hypergravity or simulated microgravity systems would fit very well in this journal.

Although commercial flight opportunities are increasing, there is still a great need for affordable and daily research possibilities. Technologies purposed for on-ground simulation of microgravity or partial gravity have been and are being developed and used in numerous labs. Manuscripts regarding current novel initiatives based on either 2D clinostats, (e.g., Gordon and Shen-Miller, 1966; Briegleb, 1968; Shi et al., 2012; Eiermann et al., 2013), or 3D Random Positioning Machines, (e.g., Hoson et al., 1997; Ichigi and Asashima, 2001; Van Loon, 2007b; Borst and Van Loon, 2008; Wuest et al., 2014; Hasenstein and Van Loon, 2015) and related algorithms, and associated artifacts, (e.g., Leguy et al., 2011, 2017; Wuest et al., 2017), are welcome.

Although this journal is called Microgravity, we also very much encourage papers regarding hypergravity or partial or reduced gravity (between $\mu$ and one), research and technology, and instrumentation. Low gravity is becoming more and more relevant in the various Space Explorations programs for missions 


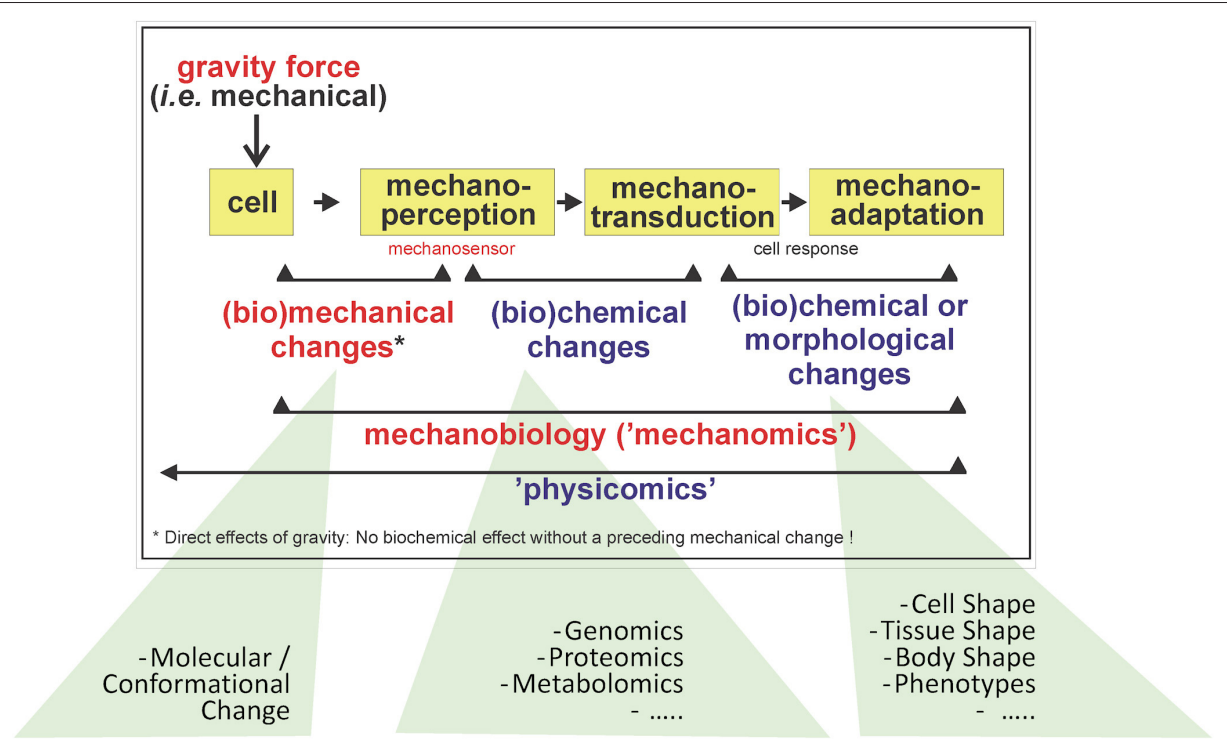

FIGURE 1 | Terminology and sequence of events in cell biomechanics/gravitational biology. In mechanobiology, we study the effects of mechanical forces within and/or applied to a cell or parts of it-this can be termed as "mechanomics." Extending this to the overall physical environment and processes around and within a cell, such as like magnetic fields, temperature, etc., we might even use the term "physicomics" (see also Van Loon, 2009).

to the Moon, see, e.g., Artemis and related Gateway programs (Duggan and Moseman, 2018; Chavers et al., 2020), and missions to Mars (International Space Exploration Coordination Group, 2018).

Hypergravity created by centrifuges or by strong magnetic fields can be very illustrative of gravity and how it has an impact on the systems of study. One could use the hypergravity data to build a model and use it to extrapolate values below one $g$ based on the gravity continuum principle, see (e.g., Firstbrook et al., 2017). One could also make use of centrifuges to simulated microgravity or lower gravity by means of the Reduced Gravity Paradigm (Van Loon, 2016).

\section{REFERENCES}

Albrecht-Buehler, G. (1991). Possible mechanisms of indirect gravity sensing by cells. ASGSB Bull. 4, 25-34.

Ardeshirpour, Y., Sackett, D. L., Knutson, J. R., and Gandjbakhche, A. H. (2018). Using in vivo fluorescence lifetime imaging to detect HER2-positive tumors. EJNMMI Res. 8, 26. doi: 10.1186/s13550-018-0384-6

Bao, G., Kamm, R. D., Thomas, W., Hwang, W., Fletcher, D. A., Grodzinsky, A. J., et al. (2010). Molecular biomechanics: the molecular basis of how forces regulate cellular function. Mol. Cell. Biomech. 3, 91-105. doi: 10.1007/s12195-010-0109-Z

Beysens, D. A., and Van Loon, J. (2015). "The space gravity environment," in Generation and Applications of Extra-Terrestrial Environments on Earth, eds D. A. Beysens and J. Van Loon (Aalborg: Rivers Publishers), 5-9. doi: $10.13052 /$ rp-9788793237544

Bianchi, S., Sosa, V. C., Vizsnyiczai, G., and Di Leonardo, R. (2020). Brownian fluctuations and hydrodynamics of a microhelix near a solid wall. Sci. Rep. 10, 1-8. doi: 10.1038/s41598-020-61451-y

Blue Origin (2017). New Shepard Payload User's Guide For Research and Education Missions. NSPM-MA0002-C Rev C. Available online at: https://www. blueorigin.com
Finally, the title of this new journal is "Microgravity," though this is not physically correct, as mentioned earlier. Free fall or near weightlessness is more accurate, but we keep on using the term since the science community as well as the general public are more familiar with it. The value " $0 \mathrm{~g}$ " (zero gravity) should be avoided, however, since no such environment exists in our solar system or beyond (Beysens and Van Loon, 2015).

\section{AUTHOR CONTRIBUTIONS}

The author confirms being the sole contributor of this work and has approved it for publication.

Borst, A. G., and Van Loon, J. J. W. A. (2008). Technology and developments for the random positioning machine, RPM. Microgravity Sci. Technol. 21, 287-292. doi: 10.1007/s12217-008-9043-2

Briegleb, W. (1968). Simulated weightlessness for the ontogenesis of the otolith organ. Naturwissenschaften 55, 397. doi: 10.1007/BF00593312

Chavers, G., Watson-Morgan, L., Smith, M., Suzuki, N., and Polsgrove, T. (2020). NASA's Human Landing System: The Strategy for the 2024 Mission and Future Sustainability. Hintsville, AL: NASA.

Corydon, T. J., Kopp, S., Wehland, M., Braun, M., Schutte, A., Mayer, T., et al. (2016). Alterations of the cytoskeleton in human cells in space proved by life-cell imaging. Sci. Rep. 6:20043. doi: 10.1038/srep20043

Crippen, R., and Young, J. (2011). Wings in Orbit: Scientific and Engineering Legacies of the Space Shuttle 1971-2010. Washington, DC: Government Printing Office.

De Vos, W. H., Beghuin, D., Schwarz, C. J., Jones, D. B., Van Loon, J. J., BereiterHahn, J., et al. (2014). Invited review article: Advanced light microscopy for biological space research. Rev. Sci. Instrum. 85:101101. doi: 10.1063/1.48 98123

Dreyer, L. (2009). "Latest developments on SpaceX's Falcon 1 and Falcon 9 launch vehicles and Dragon spacecraft," in 2009 IEEE Aerospace Conference (Big Sky, MT: IEEE), 1-15. doi: 10.1109/AERO.2009.4839555 
Duggan, M., and Moseman, T. (2018). "Deep space gateway architecture to support multiple exploration \& demonstration goals," in 2018 IEEE Aerospace Conference (Big Sky, MT: IEEE), 1-8. doi: 10.1109/AERO.2018.8396413

Eiermann, P., Kopp, S., Hauslage, J., Hemmersbach, R., Gerzer, R., and Ivanova, K. (2013). Adaptation of a 2-D clinostat for simulated microgravity experiments with adherent cells. Microgravity Sci. Technol. 25, 153-159. doi: $10.1007 /$ s12217-013-9341-1

European Space Acency (2014). "Sounding rockets," in ESA User Guide to Low Gravity Platforms, ed M. Sabbatini (Noordwijk).

Evans, C., Robinson, J., and Tate-Brown, J. (2009). "Research on the international space station: an overview," in 47th AIAA Aerospace Sciences Meeting including The New Horizons Forum and Aerospace Exposition (Orlando, FL), 186. doi: 10.2514/6.2009-186

Fedele, A., Guidotti, G., Rufolo, G., Malucchi, G., Denaro, A., Massobrio, F., et al. (2018). The Space Rider Programme: End user's needs and payload applications survey as driver for mission and system definition. Acta Astronaut. 152, 534-541. doi: 10.1016/j.actaastro.2018.08.042

Firstbrook, D., Worrall, K., Timoney, R., Sunol, F., Gao, Y., and Harkness, P. (2017). An experimental study of ultrasonic vibration and the penetration of granular material. Proc. Math. Phys. Eng. Sci. 473:20160673. doi: 10.1098/rspa.2016.0673

Frett, T., Mayrhofer, M., Schwandtner, J., Anken, R., and Petrat, G. (2014). An innovative short arm centrifuge for future studies on the effects of artificial gravity on the human body. Microgravity Sci. Technol. 26, 249-255. doi: 10.1007/s12217-014-9386-9

González-Bermúdez, B., Guinea, G. V., and Plaza, G. R. (2019). Advances in micropipette aspiration: applications in cell biomechanics, models, and extended studies. Biophys. J. 116, 587-594. doi: 10.1016/j.bpj.2019.01.004

Gordon, S. A., and Shen-Miller, J. (1966). On the thresholds of gravitational force perception by plants. Life Sci. Space Res. 4, 22-34.

Goswami, N., Blaber, A. P., Hinghofer-Szalkay, H., and Convertino, V. A. (2019). Lower body negative pressure: physiological effects, applications, and implementation. Physiol. Rev. 99, 807-851. doi: 10.1152/physrev.00006.2018

Gu, Y., Gao, M., and Zhao, G. (2016). The space sciences and application projects in space laboratory. Chin. J. Space Sci. 36, 626-632. doi: $10.11728 /$ cjss2016.05.626

Hall, T. W. (2016). "Artificial gravity in theory and practice," in 46th International Conference on Environmental Systems: 46th International Conference on Environmental Systems (Vienna).

Hasenstein, K. H., and Van Loon, J. J. (2015). "Clinostats and other rotating systems-Design, function, and limitations," in Generation and Applications of Extra-Terrestrial Environments on Earth, eds Beysens and van Loon (Aalborg: Rivers Publishers), 147-156.

Hoson, T., Kamisaka, S., Masuda, Y., Yamashita, M., and Buchen, B. (1997). Evaluation of the three-dimensional clinostat as a simulator of weightlessness. Planta 203, S187-S197. doi: 10.1007/PL00008108

$\mathrm{Hu}$, W., and Kang, Q. (2019). Physical Science Under Microgravity: Experiments on Board the SJ-10 Recoverable Satellite. Bejing: Springer. doi: 10.1007/978-981-13-1340-0

Ichigi, J., and Asashima, M. (2001). Dome formation and tubule morphogenesis by Xenopus kidney A6 cell cultures exposed to microgravity simulated with a 3Dclinostat and to hypergravity. In Vitro Cell. Dev. Biol. Anim. 37, 31-44. doi: 10. 1290/1071-2690(2001)037<0031:dfatmb>2.0.co;2

Ilyin, E. A. (2000). Historical overview of the Bion project. J. Gravit. Physiol. 7, S1-S8. doi: 10.1111/j.1528-1157.2000.tb02942.x

International Space Exploration Coordination Group (2018). The Global Exploration Roadmap. Washington, DC.

Ishioka, N., Suzuki, H., Asashima, M., Kamisaka, S., Mogami, Y., Ochiai, T., et al. (2004). Development and verification of hardware for life science experiments in the Japanese Experiment Module "Kibo" on the International Space Station. J. Gravit. Physiol. 11, 81-91.

Janmaleki, M., Pachenari, M., Seyedpour, S. M., Shahghadami, R., and SanatiNezhad, A. (2016). Impact of simulated microgravity on cytoskeleton and viscoelastic properties of endothelial cell. Sci. Rep. 6:32418. doi: $10.1038 /$ srep32418

Joosten, B. K. (2007). "Preliminary assessment of artificial gravity impacts to deepspace vehicle design," in NASA Johnson Space Center, JSC-63743. Houston, TX: NASA; Lyndon B. Johnson Space Center.
Kanikowska, D., Sato, M., Iwase, S., Shimizu, Y., Inukai, Y., Nishimura, N., et al. (2008). Immune and neuroendocrine responses to head-down rest and countermeasures. Aviat. Space Environ. Med. 79, 1091-1095. doi: 10.3357/ASEM.2301.2008

Karouia, F., Peyvan, K., and Pohorille, A. (2017). Toward biotechnology in space: High-throughput instruments for in situ biological research beyond Earth. Biotechnol. Adv. 35, 905-932. doi: 10.1016/j.biotechadv.2017.04.003

Kohn, F. P. (2013). High throughput fluorescent screening of membrane potential and intracellular calcium concentration under variable gravity conditions. Microgravity Sci. Technol. 25, 113-120. doi: 10.1007/s12217-012-9331-8

Lackner, J., and Dizio, P. (2000). Artificial gravity as a countermeasure in long-duration space flight. J. Neurosci. Res. 62, 169-176. doi: 10.1002/10974547(20001015)62:2<169::AID-JNR2>3.0.CO;2-B

Lee, H.-J., Shi, D.-L., and Zheng, J. J. (2015). Conformational change of Dishevelled plays a key regulatory role in the Wnt signaling pathways. Elife 4:e08142. doi: 10.7554/eLife.08142

Leguy, C. A., Delfos, R., Pourquie, M. J., Poelma, C., Krooneman, J., Westerweel, J., et al. (2011). Fluid motion for microgravity simulations in a random positioning machine. Gravit. Space Res. 25.

Leguy, C. A. D., Delfos, R., Pourquie, M. J. B. M., Poelma, C., Westerweel, J., and Van Loon, J. J. W. A. (2017). Fluid dynamics during Random Positioning Machine micro-gravity experiments. Adv. Space Res. 59, 3045-3057. doi: 10.1016/j.asr.2017.03.009

Li, N., Wang, C., Sun, S., Zhang, C., Lu, D., Chen, Q., et al. (2018). Microgravityinduced alterations of inflammation-related mechanotransduction in endothelial cells on board SJ-10 satellite. Front. Physiol. 9:1025. doi: 10.3389/fphys.2018.01025

Michel, E. L., Johnston, R. S., and Dietlein, L. F. (1976). Biomedical results of the Skylab Program. Life Sci. Space Res. 14, 3-18.

Mohagheghian, E., Luo, J., Chen, J., Chaudhary, G., Chen, J., Sun, J., et al. (2018). Quantifying compressive forces between living cell layers and within tissues using elastic round microgels. Nat. Commun. 9:1878. doi: 10.1038/s41467-018-04245-1

Monti, R. (2002). Physics of Fluids in Microgravity. London, UK: CRC Press. doi: $10.1201 / 9781482265057$

Nakanishi, J., Nakajima, T., Sato, M., Ozawa, T., Tohda, K., and Umezawa, Y. (2001). Imaging of conformational changes of proteins with a new environment-sensitive fluorescent probe designed for site-specific labeling of recombinant proteins in live cells. Anal. Chem. 73, 2920-2928. doi: 10.1021/ac001528p

NASA (1973). Skylab Experiments, Volume 1 Physical Science, Solar Astronomy. Washington, DC: NASA.

Nikolaev, S. O., and Ilyin, E. A. (1981). Summary of experiments onboard Soviet biosatellites. Acta Astronaut. 8, 919-926. doi: 10.1016/0094-5765(81) 90062-X

Paloski, W. H., and Charles, J. B. (2014). 2014 International Workshop on Research and Operational Considerations for Artificial Gravity Countermeasures. Hanover, MD: Editorial Board.

Pletser, V., and Kumei, Y. (2015). "Parabolic Flights," in Generation and Applications of Extra-Terrestrial Environments on Earth, eds D. A. Beysens and J. J. Van Loon (Aalborg: Rivers Publishers), 61-73.

Pollard, E. C. (1965). Theoretical studies on living systems in the absence of mechanical stress. J. Theor. Biol. 8, 113-123. doi: 10.1016/0022-5193(65)90097-4

Preu, P., and Braun, M. (2014). German SIMBOX on Chinese mission Shenzhou8: Europe's first bilateral cooperation utilizing China's Shenzhou programme. Acta Astronaut. 94, 584-591. doi: 10.1016/j.actaastro.2013.08.022

Rittweger, J., Bareille, M.-P., Clément, G., Linnarsson, D., Paloski, W. H., Wuyts, F., et al. (2015). Short-arm centrifugation as a partially effective musculoskeletal countermeasure during 5-day head-down tilt bed restresults from the BRAG1 study. Eur. J. Appl. Physiol. 115, 1233-1244. doi: 10.1007/s00421-015-3120-1

Ruttley, T. M., Robinson, J. A., and Gerstenmaier, W. H. (2017). The international space station: collaboration, utilization, and commercialization. Soc. Sci. Q. 98, 1160-1174. doi: 10.1111/ssqu.12469

Seedhouse, E. (2016). "DragonLab," in SpaceX's Dragon: America's Next Generation Spacecraft, ed C. Cressy (Dordrecht: Springer), 113-126. doi: 10.1007/978-3-319-21515-0_7 
Shi, F., Wang, Y.-C., Zhao, T.-Z., Zhang, S., Du, T.-Y., Yang, C.-B., et al. (2012). Effects of simulated microgravity on human umbilical vein endothelial cell angiogenesis and role of the PI3K-Akt-eNOS signal pathway. PLoS ONE 7:e40365. doi: 10.1371/journal.pone.0040365

Sibonga, J., Matsumoto, T., Jones, J., Shapiro, J., Lang, T., Shackelford, L., et al. (2019). Resistive exercise in astronauts on prolonged spaceflights provides partial protection against spaceflight-induced bone loss. Bone 128:112037. doi: 10.1016/j.bone.2019.07.013

Stepanek, J., Blue, R. S., and Parazynski, S. (2019). Space Medicine in the Era of Civilian Spaceflight. N. Engl. J. Med. 380, 1053-1060. doi: 10.1056/NEJMra1609012

Taylor, F. W., Allison, C. J., Lee, C. L., and Ibold, K. R. (2014). "Challenges and opportunities related to landing the Dream Chaser $®$ reusable space vehicle at a public-use airport," in Space Traffic Management Conference (Daytona Beach, FL: Embry-Riddle Aeronautical University).

Thiel, C. S., Tauber, S., Lauber, B., Polzer, J., Seebacher, C., Uhl, R., et al. (2019). Rapid morphological and cytoskeletal response to microgravity in human primary macrophages. Int. J. Mol. Sci. 20, 2402. doi: 10.3390/ijms20102402

Todd, P. (1989). Gravity-Dependent Phenomena at the Scale of the Single Cell. ASGSB Bull. 2, 95-113.

Trepat, X., Deng, L., An, S. S., Navajas, D., Tschumperlin, D. J., Gerthoffer, W. T., et al. (2007). Universal physical responses to stretch in the living cell. Nature 447, 592-595. doi: 10.1038/nature05824

Van Loon, J. J. (2007a). Micro-gravity and mechanomics. Gravit. Space Res. $20,3-17$.

Van Loon, J. J., Cras, P., Roozendaal, W., Bouwens, W., and Vernikos, J. (2020). Gravity deprivation: is it ethical for optimal physiology? Front. Physiol. 11:470. doi: 10.3389/fphys.2020.00470

Van Loon, J. J., Medina, F. J., Stenuit, H., Istasse, E., Heppener, M., and Marco, R. (2007). The national-esa soyuz missions andromède, marco polo, odissea, cervantes, delta and eneide. Microgravity Sci. Technol. 19:9. doi: 10.1007/BF02919448

Van Loon, J. J., Van Laar, M. C., Korterik, J. P., Segerink, F. B., Wubbels, R. J., De Jong, H. A., et al. (2009). An atomic force microscope operating at hypergravity for in situ measurement of cellular mechano-response. J. Microsc. 233, 234-243. doi: 10.1111/j.1365-2818.2009.03113.x

Van Loon, J. J. W. A. (2007b). Some history and use of the random positioning machine, RPM, in gravity related research. Adv. Space Res. 39, 1161-1165. doi: 10.1016/j.asr.2007.02.016

Van Loon, J. J. W. A. (2009). Mechanomics and Physicomics in Gravisensing. Microgravity Sci. Technol. 21, 159-167. doi: 10.1007/s12217-008-9065-9

Van Loon, J. J. W. A. (2016). Centrifuges for microgravity simulation. The reduced gravity paradigm. Front. Astron. Space Sci. 3:21. doi: 10.3389/fspas.2016.00021
Van Loon, J. J. W. A., Baeyens, J. P., Berte, J., Blanc, S., Braak, L., Bok, K., et al. (2012). A large human centrifuge for exploration and exploitation research. Ann. Kinesiol. 3.

Virgin Galactic (2016). SpaceShipTwo: An Introductory Guide for Payload Users. Santa Fe, NM: Virgin Galactic.

Von Kampen, P., Kaczmarczik, U., and Rath, H. J. (2006). The new Drop Tower catapult system. Acta Astronaut. 59, 278-283. doi: 10.1016/j.actaastro.2006.02.041

Vorselen, D., Roos, W. H., Mackintosh, F. C., Wuite, G. J., and Van Loon, J. J. (2014). The role of the cytoskeleton in sensing changes in gravity by nonspecialized cells. FASEB J. 28, 536-547. doi: 10.1096/fj.13-236356

Wang, L., Han, F., and Zheng, H. Q. (2018). Photoperiod-controlling guttation and growth of rice seedlings under microgravity on board Chinese spacelab TG-2. Microgravity Sci. Technol. 30, 839-847. doi: 10.1007/s12217-0189644-3

Wang, S., Wang, K., Zhou, Y., Yan, B., Li, X., Zhang, Y., et al. (2019). Development of the varying gravity rack (VGR) for the Chinese space station. Microgravity Sci. Technol. 31, 95-107. doi: 10.1007/s12217-018-9670-1

Woodcock, E. M., Girvan, P., Eckert, J., Lopez-Duarte, I., Kubankova, M., Van Loon, J., et al. (2019). Measuring intracellular viscosity in conditions of hypergravity. Biophys. J. 116, 1984-1993. doi: 10.1016/j.bpj.2019.03.038

Wuest, S. L., Richard, S., Walther, I., Furrer, R., Anderegg, R., Sekler, J., et al. (2014). A novel microgravity simulator applicable for three-dimensional cell culturing. Microgravity Sci. Technol. 26, 77-88. doi: 10.1007/s12217-014-9364-2

Wuest, S. L., Stern, P., Casartelli, E., and Egli, M. (2017). Fluid dynamics appearing during simulated microgravity using random positioning machines. PLoS ONE 12:e0170826. doi: 10.1371/journal.pone.0170826

Young, L., Yajima, K., and Paloski, W. (2009). Artificial Gravity Research to Enable Human Space Exploration. Paris: International Academy of Astronautics.

Zhou, S., Yang, X., Hu, J., Mo, C., Cao, Y., and Yang, C. (2018). Continuous hypergravity alters the cytoplasmic elasticity of MC3T3-E1 osteoblasts via actin filaments. J. Biomech. 72, 222-227. doi: 10.1016/j.jbiomech.2018.02.024

Conflict of Interest: The author declares that the research was conducted in the absence of any commercial or financial relationships that could be construed as a potential conflict of interest.

Copyright (c) 2020 van Loon. This is an open-access article distributed under the terms of the Creative Commons Attribution License (CC BY). The use, distribution or reproduction in other forums is permitted, provided the original author(s) and the copyright owner(s) are credited and that the original publication in this journal is cited, in accordance with accepted academic practice. No use, distribution or reproduction is permitted which does not comply with these terms. 